\title{
Rafael NaVArro-Valls y Javier Martínez-Torrón, Conflictos entre con- ciencia y ley, Iustel, Madrid, 2011, 514 pp.
}

Con la obra que aquí se reseña, los profesores Navarro-Valls y MartínezTorrón nos ofrecen, probablemente, el trabajo más amplio y mejor documentado que existe en nuestra literatura jurídica acerca de los conflictos que pueden suscitarse entre conciencia y ley. Lejos de sus pretensiones está la elaboración de una teoría general de la objeción de conciencia; por el contrario, abordan el tema desde una perspectiva tópica, centrada en la casuística. Esta metodología - tan habitual en el quehacer jurídico- es fruto del convencimiento de que, ante la heterogeneidad de los conflictos que se plantean y la variedad de soluciones que se proponen, una tesis general excesivamente dogmática, alejada del caso concreto, corre el riesgo de producir resultados injustos al ser aplicada. No se le oculta al lector, sin embargo, un principio rector de la obra, una indisimulada disposición de fondo de delicadeza y respeto hacia las conciencias. Se trata, en realidad, de una actitud necesaria en una sociedad pluralista, que no puede desconocer las convicciones sinceras de grandes y pequeñas minorías de diverso signo - ciudadanos en todo caso-que habitan en el interior de sus fronteras. Sin perjuicio de este principio general, los autores se resisten, como se ha indicado, a dar respuestas excesivamente generales: una aceptación global de la objeción, sin matiz alguno, conduciría efectivamente a la disolución del orden jurídico; mas tampoco es admisible la solución contraria, esto es, rechazar con carácter general la objeción bajo el pretexto de evitar una «tiranía de las conciencias». No cabría siquiera, como a veces se pretende, identificar «objeción» con «insumisión», porque la objeción no emana de un mero infractor de la ley, sino que presupone -y esto es decisivo- un conflicto interior hacia el cual la Constitución no permanece insensible (p. 33): al contrario, la conciencia moral de la persona es un bien iusfundamental protegido por el art. $16 \mathrm{CE}$. Vista de este modo, «la objeción de conciencia debe perder su trasfondo de 'ilegalidad más o menos consentida'» (p. 59), y los problemas que se suscitan con ocasión de ella han de solventarse, al igual que otros casos de derechos fundamentales, a partir de un balancing process «que determine cuándo debe prevalecer la opción asumida en conciencia y cuándo han de primar otros intereses sociales que resulten afectados en esa concreta situación» (p. 61).

Sin llegar, como hemos dicho, a una teoría general de la objeción, los autores trazan algunos criterios orientadores para demarcar «las líneas de fuerza por las que podría transitar la garantía jurídica de la objeción de conciencia» (p. 67). En este punto es forzoso reconocer, no obstante, que no están todos los que son. Un criterio tan importante como el del «interés» tutelado por el deber objetado -que lleva a distinguir entre obligaciones en interés del destinatario, en interés de terceros y en interés público-, postulado por Raz en The Authority of Law, no figura entre los expuestos por los autores. No 
obstante, el gran mérito del libro no es, como ya se ha dicho, lo que tiene de teoría general, sino el autorizado y vasto análisis jurisprudencial y legal.

Después de dos capítulos dedicados a las aludidas consideraciones generales, los autores entran de lleno en lo que califican como un auténtico big bang de objeciones de conciencia (p. 25). Demuestran aquí, valga la insistencia, un conocimiento extraordinario de la jurisprudencia y la legislación nacional, supranacional y comparada. Las decisiones comentadas no son conocidas sólo superficialmente, sino que se aprecia una verdadera indagación en las particularidades de cada caso y una gran atención a las opiniones discrepantes. El Capítulo Tercero abre el análisis de particulares conflictos con el examen de la objeción militar, reconocida amplísimamente en el Derecho comparado (pp. 96 y ss.). El art. 4.3.b) CEDH admite, sin embargo, la posibilidad de que no se reconozca este derecho, motivo por el que no existe un pronunciamiento del Tribunal de Estrasburgo que lo afirme. Al redactar estas líneas se haya aún pendiente de resolución en la Gran Sala el caso Bayatyan c. Armenia, sobre el que recayó una primera sentencia desestimatoria el 27 de octubre de 2009.

El siguiente Capítulo lo dedican los autores a la objeción fiscal al pago de la cuota impositiva destinada a actividades contrarias a la propia conciencia, v. gr. las actividades militares o el aborto. La objeción fiscal ha sido generalmente rechazada en países como Estados Unidos, Italia o España (ATC 71/1993, de 1 marzo), sobre el bien fundado argumento de las consecuencias funestas que tendría la exención al «deber de contribuir» del artículo $31 \mathrm{CE}$ y, sobre todo, del principio de no afectación del impuesto. Es interesante el caso de Holanda, donde se acepta la objeción de los adeptos a las iglesias de origen menonita a las contribuciones de la Seguridad Social, si bien se les obliga a pagar la misma cantidad como impuesto sobre la renta (p. 115). En junio de 2005, fracasó una proposición de ley presentada por ERC que pretendía eximir de pagar la parte de la cuota equivalente al porcentaje del Presupuesto destinado a gastos militares para destinarla a otro tipo de organizaciones dedicadas al fomento de la paz y de la solidaridad (p. 117).

Un tercer campo analizado en el libro es el de la objeción de conciencia al aborto. Nuestro Tribunal Constitucional la ha situado al cobijo del artículo 16 CE en la STC 53/1985. Además, tanto la objeción a la cooperación directa como a la indirecta han sido ampliamente reconocidas en el Derecho comparado (Estados Unidos, Alemania, Francia, Bélgica, Dinamarca, etc.). En contraste con esta extendida praxis, el art. 19.2 de la LO 2/2010 reconoce el derecho, sin demasiadas precisiones, a «los profesionales sanitarios directamente implicados en la interrupción voluntaria del embarazo». Este inseguro reconocimiento es severamente criticado por los autores, así como el inciso legal que, en el mismo precepto, parece subordinar el derecho fundamental a la objeción a la efectividad del aborto, incluso en aquellos casos en que no concurran razones médicas. Son también objeto de estudio, posteriormente, otras objeciones bioéticas, v. gr., las que se pueden plantear en relación con 
la clonación, la reproducción humana asistida, el diagnóstico prenatal con fines eugenésicos, la eutanasia y las llamadas objeciones farmacéuticas -referidas a la dispensa de fármacos cuyo uso o consumo puede ser razonablemente considerado como inmoral por el objetor. En relación con esto último, los autores refieren la difundida tendencia legislativa norteamericana al reconocimiento explícito, en diversos estados, de la objeción de conciencia a la expedición de fármacos de emergency contraception con posibles efectos abortivos. El Tribunal Europeo de Derechos Humanos ha negado, por el contrario, la relevancia de esta materia para los derechos del Convenio (Decisión Pichon y Sajous c. Francia, de 2 de octubre de 2001; vid. pp. 176 y ss.).

Abundan también las objeciones de conciencia a los tratamientos médicos, asunto bien conocido en nuestro país a raíz, sobre todo, de la STC $154 / 2002$. El caso versaba sobre la responsabilidad criminal de unos padres que, por motivos de conciencia, se negaron a convencer a su hijo menor, a la postre fallecido, de que aceptase una transfusión de sangre. Objeciones como ésta -en las que entran en conflicto bienes jurídicos de extraordinaria importancia- requieren sumo cuidado en el análisis de los hechos, y son muy expresivas de lo difícil que es formular una teoría general de la objeción. En el caso aludido, teniendo en cuenta que lo que había en juego era una condena penal basada en una conducta insuficientemente tipificada, prevaleció -a mi modo de ver acertadamente- la libertad religiosa de los progenitores. No sucedió lo mismo -también justamente, desde mi punto de vista- ante la querella de unos padres contra un juez que autorizó la hemotransfusión forzosa a su hija en peligro de muerte (STS 26 de septiembre de 1978). No puede hablarse, pues, de una prevalencia in abstracto de uno de los bienes jurídicos, sino que ha de estarse a la concreta relación sub examine.

En el ámbito educativo, las objeciones de conciencia han sido también numerosas. Las ceremonias religiosas o de contenido ideológico en las escuelas han dado lugar a numerosos conflictos, desde los flag salute cases resueltos por la jurisprudencia norteamericana -la negativa de los Testigos de Jehová a participar del «saludo a la bandera» por motivos religiosos- pasando por las SSTEDH Efstratiou y Valsamis, de 18 de diciembre de 1996 -sanción de unos Testigos de Jehová por negarse a participar en ceremonias nacionales sobre la base de que se conmemoraba una guerra. En el examen de los casos aludidos, los autores se muestran críticos con la excesiva primacía que los Tribunales suelen darle al «deber cívico» frente a la conciencia individual que, como bien iusfundamental, forma parte del orden público y del civismo representado por el constitucionalismo liberal. Entienden que los Tribunales sobredimensionan en ocasiones las consecuencias reales que posee la inasistencia a estas ceremonias para la cohesión cívica, y desestiman, por el contrario, la dimensión igualmente cívica e institucional del respeto a las conciencias. En este mismo Capítulo se analizan otras cuestiones tan delicadas como el home schooling, aceptado en países como Estados Unidos ( $c f r$. especialmente, el casos Yoder, de 1972, sobre el home schooling entre los Amish) 
y rechazado, por el contrario, en otros como Alemania ( $c f r$. ATCF de 31 mayo 2006) o el nuestro (art .9 LO 10/2002; cfr. STC 133/2010). Se trata de una cuestión problemática, en relación con la cual no cabe olvidar la importancia del todo capital que en la educación tiene la convivencia social.

Tampoco puede desconocerse, de todos modos, la peligrosa tentación del adoctrinamiento, en la que en ocasiones caen los poderes públicos. Es éste un problema tratado a continuación, en un extenso epígrafe sobre la «objeción de conciencia a ciertos contenidos docentes» (pp. 248 y ss.). El asunto ha suscitado una gran tensión en nuestro país en los últimos años, a raíz de las objeciones masivas a la asignatura Educación para la Ciudadanía. Como es bien sabido, la jurisprudencia del Tribunal Supremo ha negado que pueda probarse un «afán adoctrinador» (SSTS 340, 314 y 342/2009), aunque no parece desconocer el riesgo de que se den numerosas lesiones en su aplicación. Habría sido deseable -entienden los autores, con acierto en mi opinión«poner el acento no en el fin pretendido sino en el efecto adoctrinador» (p. 291; la cursiva es mía). El problema no es abordado sólo, de todos modos, a la luz del caso español, sino que se hace un examen de fondo más amplio, atendiendo a la jurisprudencia comparada (Estados Unidos, Alemania, Canadá, Inglaterra, etc.) y a la del Tribunal Europeo de Derechos Humanos.

Un Capítulo específico -el más extenso de la obra- es dedicado al problema de la libertad de conciencia y los símbolos religiosos. Aquí, merece un estudio particular y amplio el problema del velo islámico, asunto de gran complejidad en el que, una vez más, resultaría excesivamente aventurado reducir a la unidad de tratamiento la variedad de conflictos que existen. Por una parte, los autores advierten que no todos los velos son iguales, pues nuestra cultura choca más virulentamente con el burka o con el niqab -donde sólo los ojos permanecen desvelados- que con el hijab, que deja al descubierto la forma ovalada del rostro. Tampoco son iguales todas las prohibiciones, ni en lo que respecta a su ámbito espacial ni, sobre todo, al interés tutelado. Aquí, la prohibición en interés de la mujer, al entrar en conflicto con la conciencia de ésta, corre el riesgo de caer en el paternalismo denunciado por Raz; la prohibición en interés de la seguridad pública, sin embargo, es fácilmente defendible en muchos casos.

Entre los conflictos que se han suscitado con ocasión de los símbolos religiosos, se encuentra muy vivo en nuestra mente el caso Lautsi c. Italia. Navarro-Valls y Martínez-Torrón formulan importantes objeciones a la Sentencia de la Sala (pp. 386-387), si bien la de la Gran Sala, del pasado 18 de marzo, fue posterior a la edición de libro. Los autores entienden que el primer pronunciamiento empleó el discurso de los derechos de un modo excesivamente expansivo. En Alemania, tras la polémica Sentencia que declaró inconstitucional la ley bávara que, sobre la base de las tradiciones locales, preveía la presencia del crucifijo (STCF 93, 1, de 16 de mayo de 1995), el Parlamento del Land lo mantuvo añadiendo -en cumplimiento de los requerimientos de la sentencia- un procedimiento para llegar a un acuerdo en caso de contro- 
versias (vid. art. 7.3 Bayerisches Gesetz über das Erziehungs- und Unterrichtswesen). Aun sin compartir totalmente la solución final, entiendo que, en casos como éste, el compromiso político entre los legítimos intereses de la mayoría y la visión, también legítima, de las minorías, constituye una vía más acertada que la victoria definitiva a través de los derechos. Como expuso hace ya años en un magnífico libro la profesora Mary Ann Glendon -y como el itinerario mismo seguido por el caso Lautsi ha demostrado-, parece que este tipo de uso del lenguaje de los derechos «aumenta la posibilidad del conflicto e inhibe el tipo de diálogo crecientemente necesario en una sociedad pluralista» (GLENDON, M. A., Rights talk. The Impoverishment of Political Discourse, The Free Press, Nueva York, 1991, pp. 44-45). Probablemente, lo que la señora Lautsi discutía era una cuestión de Derecho objetivo, esto es, propugnaba un modelo determinado de laicidad. No es sin embargo claro, y así parece corroborarlo la Sentencia de la Gran Sala del pasado 18 de marzo, que Estrasburgo hubiese de darle una respuesta estimatoria desde los derechos humanos, por encima de la diversidad de costumbres y tradiciones constitucionales europeas.

En el décimo Capítulo son objeto de estudio los conflictos de conciencia que en ocasiones se suscitan en las relaciones laborales. Conversos al judaísmo ortodoxo, a la Iglesia Adventista del Séptimo Día, a la Congregación Cristiana de los Testigos de Jehová y a otros grupos minoritarios han objetado en numerosas ocasiones al trabajo en sábado. Los sabbatarian cases, abundantes en Estados Unidos, han dado lugar a una jurisprudencia cuyo punto de partida es el caso Sherbert, de 1963. En aquella ocasión, se le había negado el subsidio de desempleo a una trabajadora perteneciente a la Iglesia Adventista del Séptimo Día que, al ampliarse el calendario laboral, fue despedida por negarse a trabajar en sábado. La Administración entendía que el abandono del trabajo, motivado por razones religiosas, no obedecía a una causa justa, idea que fue rechazada por el Tribunal Supremo (pp. 400 y ss.). Son numerosos los casos que se han planteado con posterioridad, sin que sea posible, una vez más, determinar la prevalencia absoluta de uno de los principios en conflicto. En España, la STC 19/1985, de 13 de febrero, dio la razón al empresario ante la conversión de una trabajadora a la Iglesia Adventista del Séptimo Día que no podía trabajar en sábado por motivos de conciencia. Los autores se muestran disconformes respecto a la falta de matiz de la Sentencia y a la escasa valoración de circunstancias tan relevantes como la posibilidad de un acomodo entre los intereses de una y otra parte (pp. 435-437). Ésta es la línea seguida, por lo demás, en Canadá, país modélico, según los autores, en la búsqueda de una «acomodación razonable» (reasonable accomodation) entre la conciencia del trabajador y los intereses del empresario, siempre que no le suponga a este último un «gravamen excesivo» (undue hardship) (vid. pp. 412-419).

El libro se cierra con dos capítulos dedicados respectivamente a la objeción de conciencia y función pública y a la objeción de conciencia en orde- 
namientos confesionales. La objeción a actuar como jurado, el problema de los juramentos promisorios -tema pacíficamente resuelto, con carácter general-, la objeción al participar en la celebración de matrimonios entre homosexuales o el problema del secreto de confesión son algunos de los conflictos con que el libro se cierra.

Volviendo a las consideraciones del comienzo, la obra que se reseña constituye una referencia indispensable para conocer la casuística sobre conflictos entre conciencia y ley $\mathrm{y}$, seguramente, una buena herramienta para reflexionar sobre nuestra propia convivencia. La religión y, más en general, las convicciones morales íntimas, no se pueden tratar -subrayan los autores, siguiendo al profesor de Yale Stephen L. Carter- «como un hobby: algo tan privado y tan irrelevante para la sociedad como el aeromodelismo» (p. 437). El fino respeto a las conciencias, unido a la determinación por preservar el interés público, son ambos elementos necesarios para la cohesión social y la convivencia tolerante. Estamos ante el reto de encontrar soluciones compartidas y eficaces, y el libro que aquí se reseña nos ofrece abundantes materiales $y$ casos reales que contribuyen, a mi modo de ver, a adquirir una mayor conciencia cívica para abordar esta tarea.

Fernando Simón Yarza Universidad de Navarra 